\title{
Pygmalion Effect: Its Application in Classroom
}

\section{Divya $\mathrm{R}^{*}$}

Department of Physiology, Dhanalakshmi Srinivasan Medical college and Hospital, The Tamilnadu Dr MGR Medical university, India

*Corresponding author: Divya R, Associate professor, Department of Physiology, Dhanalakshmi Srinivasan Medical college and Hospital, The Tamilnadu Dr MGR Medical university, Perambalur, Tamilnadu, India

\section{The Pygmalion Effect}

Robert Rosenthal demarcated Pygmalion effect as "the phenomenon whereby one person's behavior comes to serve as a self-fulfilling prophecy" Research studies byRosenthal and Jacobsen (1968), amongst others, illustrates that the expectations of a teacher has a greater influence on the performance of the student. Superior expectations influence performance. Positive reinforcement can produce good results. Individuals who expect more, get more. Optimistic expectations has an impact on the performance positively, besides negative expectations affect the performance negatively[1] (Figure 1).

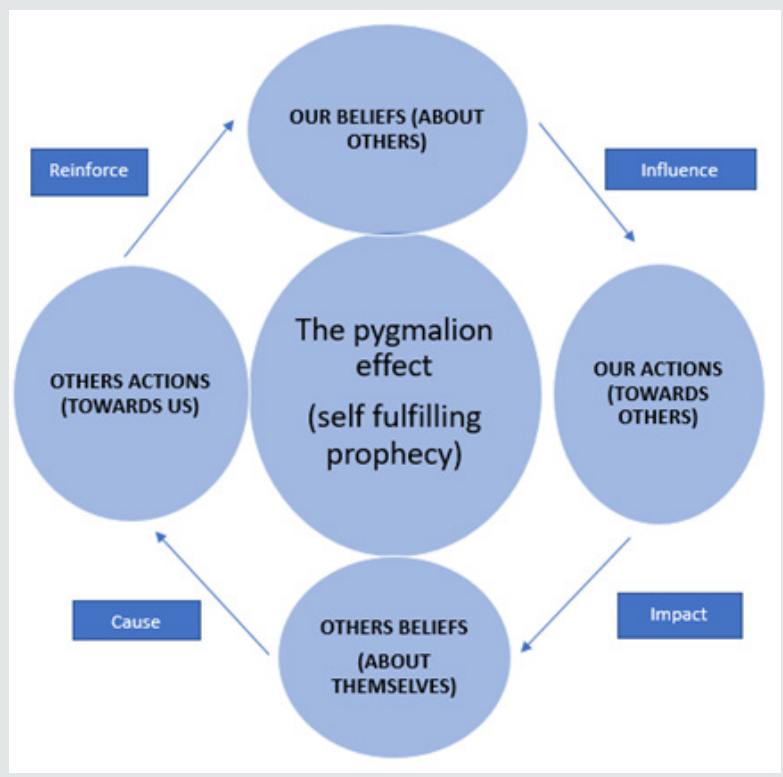

Figure 1: The Pygmalion Effect.

Rosenthal and Jacobson formerly defined this phenomenon as the Pygmalion Effect. They engrossed on an experimentation at an elementary school where the students did pre-tests on intelligence.
Rosenthal and Jacobsen then identified with the teachers of the names of $20 \%$ of the students in the school who were presenting "uncommon talent for intellectual growth" and would come up educationally during the year. Without the knowledge of the teachers, these students were nominated haphazardly with no connection to the initial pre- test results. After a duration of eight months the students were tested by Rosenthal and Jacobson. It was found out that the haphazardly nominated students who teachers believed would do well recorded considerably higher scores. Rosenthal also claims that the Pygmalion effect is also applicable for the higher education system too [2].

\section{Golem Effect}

Golem effect is the reverse of the Pygmalion effect.it signifies that low-slung expectations may lead to either self-handicapping activities or a self-fulfilling forecast, with students deteriorating as they as well as their teachers do not have a belief that they will do well[3].

\section{Conclusion}

No one upsurges to low-slung expectations. The key to each and every student reaching their best ability is by enduring higher levels of expectations and by catering the required support necessitated backing to accomplish that level. It is also needed to put into students the words of higher expectations. It is essential to Launch high expectations among the students. when faculty have advanced expectations the achievement by the Students will be further increased. When the students are given a tough project, it is required to use phrases such as, "I know you can do this." If it is genuinely thought that the students cannot complete the project, then try to shelve the project and re-explain the subject of concern. Failure should never be predicted in the classroom. If a test is principally tough, students must be told that the test is tough, but 
they will do well if they labor hard.This will surely help the students accomplish even the most difficult goals and will be a driving force to increase their self-confidence and their ideals.

\section{References}

1. Jie C (2011) A Case Study of the "Pygmalion Effect": Teacher Expectations and Student Achievement. International Education Studies 4(1): 198201.
2. Susan H McLeod (1995) "Pygmalion or Golem? Teacher Affect and Efficacy." College Composition and Communication 46 (3): 369-386.

3. Rosenthal R, Jacobsen L (1968) Pygmalion in the classroom: teacher expectation and pupils' intellectual development. Holt, Rinehart and Winston: New York, USA.

\section{(c) (i) \\ This work is licensed under Creative Commons Attribution 4.0 License}

To Submit Your Article Click Here: Submit Article

Online Journal of Neurology
and Brain Disorders
Assets of Publishing with us

